\title{
Solubility of Phenothiazine in Water, Ethanol, and Propylene Glycol at (298.2 to 338.2) K and Their Binary and Ternary Mixtures at $298.2 \mathrm{~K}$
}

\author{
Somaieh Ahmadian, ${ }^{\dagger}$ Vahid Panahi-Azar, ${ }^{\ddagger}$ Mohammad A. A. Fakhree, ${ }^{\S}$ William E. Acree, Jr.," and \\ Abolghasem Jouyban ${ }^{*,+}$ \\ ${ }^{\dagger}$ Drug Applied Research Center and Faculty of Pharmacy, ${ }^{\ddagger}$ Liver and Gastrointestinal Diseases Research Center, and ${ }^{\S}$ Biotechnology \\ Research Center, Tabriz University of Medical Sciences, Tabriz 51664, Iran \\ "Department of Chemistry, University of North Texas, Denton, Texas 76203-5070, United States
}

ABSTRACT: The solubilities of phenothiazine in water, ethanol, and propylene glycol were measured at (298.2 to 338.2) K. Also, the solubility of phenothiazine in binary mixtures of ethanol + water, propylene glycol + water, and ethanol + propylene glycol, and the ternary mixture of ethanol + propylene glycol + water was investigated. The van't Hoff equation was used to correlate the solubility of phenothiazine in monosolvents at different temperatures. The solubility values of phenothiazine in binary and ternary mixtures of solvents were calculated using the Jouyban-Acree model (Jouyban, A.; Acree, W. E., Jr. J. Chem. Eng. Data 2009, 54, 1168-1170). The mean deviation was used as an error criterion. The overall mean deviation of correlated solubility data in monosolvents at different temperatures and in mixed solvents at $298.2 \mathrm{~K}$ were $2.8 \%$ and $14.2 \%$, respectively.

\section{INTRODUCTION}

Solubility is an important physicochemical property which plays basic role in most pharmaceutical and industrial processes. To investigate this property different tools have been used such as experimental techniques, mathematical calculations, and simulation. Usually the low solubility of pharmaceutical compounds causes them to fail during the drug development process. Different factors influence the solubility in a medium, some of which include cosolvents, temperature, $\mathrm{pH}$ of the solution, and presence of surfactants.

Phenothiazine, a triheterocyclic compound (see Figure 1 for its structure), is a veterinary antihelminthic drug, and its derivatives are widely used in pharmacotherapy. Phenothiazine is one of the oldest lead compounds in medicinal chemistry, synthesized in 1883, and clinical applications of the generated drugs from this lead compound were reported in 1891 as antimalaria drug, in 1930s as antifungal, in 1940s as antihelmentic, in 1947 as antihistaminic, in 1951 as antipsychotic, in 1990 as antioxidant, and in 2009 as a promising drug in Alzheimer disease. ${ }^{1}$ Solubility data of phenothiazine could be valuable in pharmaceutical applications as many phenothiazine derivatives are of the main and important pharmaceutical compounds. Hoover et al. ${ }^{2}$ previously presented mathematical correlation of phenothiazine solubilities in organic solvents with the Abraham solvation parameter model following experimental determination of this solute in monosolvents at $298.2 \mathrm{~K}^{2}$ To the best of our knowledge, these are the only reported solubility data for phenothiazine in the literature. Thermodynamic parameters, solubilities, and interactions with micelles of a number of phenothiazine derivative drugs were investigated by Mandal et al. ${ }^{3-5}$

The aims of this study are to determine the solubility of phenothiazine in water, ethanol, and propylene glycol at (298.2 to 338.2$) \mathrm{K}$ and in ethanol + water, propylene glycol + water, ethanol + propylene glycol, and ethanol + propylene glycol + water mixtures at $298.2 \mathrm{~K}$. In addition, the solubility correlations

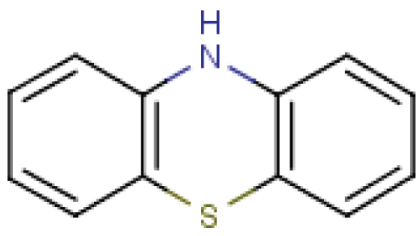

Figure 1. Chemical structure of phenothiazine.

of phenothiazine in the monosolvents at different temperatures and their mixtures are investigated.

\section{EXPERIMENTAL METHOD}

Materials. Phenothiazine with the Chemical Abstracts Service (CAS) number of 92-84-2 and International Union of Pure and Applied Chemistry (IUPAC) name of $10 \mathrm{H}$-phenothiazine (purity $>0.98$ in mass fraction) was purchased from Merck (Germany) and recrystallized from acetone to obtain a purified sample with melting point of $456 \mathrm{~K}$. The measured solubilities at 298.2 K in a number of monosolvents were also compared with available experimentally measured data from the literature (see Results and Discussion section). ${ }^{2}$ Ethanol (0.999 in mass fraction) and propylene glycol (0.995 in mass fraction) were purchased from Scharlau Chemie (Spain). Double-distilled water with a conductance of $<1.5$ microsiemense was used.

Apparatus and Procedures. The solubility of phenothiazine in ethanol, propylene glycol, and water was measured at (298.2, $308.2,318.2,328.2$, and 338.2) K. An excess amount of the solid was poured into monosolvents and incubated in ovens

Special Issue: Kenneth N. Marsh Festschrift

Received: February 15, 2011

Accepted: $\quad$ May 23, 2011

Published: June 02, 2011 
at $(298.2 \pm 0.2,308.2 \pm 0.2,318.2 \pm 0.4,328.2 \pm 0.4$, and 338.2 $\pm 0.6) \mathrm{K}$ (Behdad, Tehran, Iran), for three days. The samples were shook manually three times a day to ensure the equilibration. The results of a previous paper revealed that one day (often longer) is enough to reach equilibration condition using periodic agitation. ${ }^{2}$ To prepare the binary and ternary solvent mixtures, appropriate volumes of the solvents were mixed together. The solvents' mole fractions were computed using the densities of the pure solvents. The solvent composition could be calculated to 0.001 mole fraction. The solubility of phenothiazine was determined by equilibrating an excess amount of the solid with the binary and ternary solvent mixtures using a shaker (Behdad, Tehran, Iran) which are incubated in a temperature-controlling system at $298.2 \pm 0.2 \mathrm{~K}$ (Nabziran, Tabriz, Iran). All recrystallization and incubation processes were done under light proofed conditions. The solutions were filtered using hydrophilic Durapore filters $(0.45 \mu \mathrm{m}$, Millipore, Ireland). All of the solutions except water were diluted by ethanol; however, water solution samples were diluted by water. For aqueous solutions at (298.2 and 308.2) K, because of very low solubility, no dilution was required, and aqueous solutions at other temperatures were diluted with water. As phenothiazine is dissolved in water significantly less than in ethanol, we have used two calibration curves for water and ethanol diluted samples. Spectrophotometric analysis was performed at $317 \mathrm{~nm}$ for all of the samples except of the water samples, which were assayed at $250 \mathrm{~nm}$ with a UV-vis spectrophotometer (Beckman DU-650, Fullerton, USA). Concentrations of the diluted solutions were computed using two UV absorbance calibration graphs with the molar absorptivities of phenothiazine ranging from $\varepsilon=3321.167$ $\left(\mathrm{L} \cdot \mathrm{mol}^{-1} \cdot \mathrm{cm}^{-1}\right)$ to $\varepsilon=9963.5\left(\mathrm{~L} \cdot \mathrm{mol}^{-1} \cdot \mathrm{cm}^{-1}\right)$ and concentrations ranging from $\left(1.004 \cdot 10^{-4}\right.$ to $\left.3.011 \cdot 10^{-4}\right) \mathrm{mol} \cdot \mathrm{L}^{-1}$ for the phenothiazine solutions diluted with ethanol and from $\varepsilon=$ $39854\left(\mathrm{~L} \cdot \mathrm{mol}^{-1} \cdot \mathrm{cm}^{-1}\right)$ to $\varepsilon=199270\left(\mathrm{~L} \cdot \mathrm{mol}^{-1} \cdot \mathrm{cm}^{-1}\right)$ with the concentrations ranging from $\left(5.018 \cdot 10^{-6}\right.$ to $\left.2.509 \cdot 10^{-5}\right)$ $\mathrm{mol} \cdot \mathrm{L}^{-1}$ for aqueous samples. Each experimental data point is the mean of at least three independent measurements with the measured $\mathrm{mol} \cdot \mathrm{L}^{-1}$ solubilities reproducible to within the mean relative standard deviations (RSDs) of $2.3 \%$ and $2.7 \%$ in monosolvents at different temperatures and mixed solvents at $298.2 \mathrm{~K}$, respectively. Calculated standard deviations ranged from $\sigma_{n-1}=$ $1.6 \cdot 10^{-7}$ to $\sigma_{n-1}=1.1 \cdot 10^{-2} \mathrm{~mol} \cdot \mathrm{L}^{-1}$ and $\sigma_{n-1}=3.4 \cdot 10^{-8}$ to $\sigma_{n-1}=7.5 \cdot 10^{-3} \mathrm{~mol} \cdot \mathrm{L}^{-1}$ at different temperatures and mixtures of solvents, respectively. Densities of the saturated solutions were obtained using a $5 \mathrm{~mL}$ pycnometer with the method uncertainty of $0.001 \mathrm{~g} \cdot \mathrm{cm}^{-3}$ as a single determination.

Computational Methods. Solubility models such as modified separation of cohesive energy density (MOSCED), universal functional activity coefficient (UNIFAC), nonrandom two-liquid segment activity coefficient (NRTL-SAC), and the JouybanAcree models have been previously used for solubility correlation or prediction. Among these models, the Jouyban-Acree model which was exploited in this manuscript is able to correlate solubility with acceptable error. The basic Jouyban-Acree model is ${ }^{6}$

$$
\log C_{\mathrm{m}, T}^{\mathrm{Sat}}=x_{1} \log C_{1, T}^{\mathrm{Sat}}+x_{2} \log C_{2, T}^{\mathrm{Sat}}+\frac{x_{1} x_{2}}{T} \sum_{i=0}^{2} J_{i}\left(x_{1}-x_{2}\right)^{2}
$$

where $C_{\mathrm{m}, T}^{\mathrm{Sat}}, C_{1, T}^{\mathrm{Sat}}$, and $C_{2, T}^{\mathrm{Sat}}$ are the solubility $\left(\mathrm{mol} \cdot \mathrm{L}^{-1}\right)$ of the solute in a mixture of solvents, solvent 1 , and solvent 2 , respectively; $x_{1}$ and $x_{2}$ are the mole fractions of solvents 1 and 2 in the absence of the solute (if $\log C_{1, T}^{\text {Sat }}>\log C_{2, T}^{\text {Sat }}$ ), and $J_{i}$ coefficients are the solvent-solvent and solute-solvent interaction terms. These constant terms can be obtained by no-intercept leastsquares regression of $\left(\log C_{\mathrm{m}, T}^{\mathrm{Sat}}-x_{1} \log C_{1, T}^{\text {Sat }}-x_{2} \log C_{2, T}^{\text {Sat }}\right)$ against $\left(x_{1} x_{2}\right) / T,\left(x_{1} x_{2} \cdot\left(x_{1}-x_{2}\right)\right) / T$, and $\left(x_{1} x_{2} \cdot\left(x_{1}-x_{2}\right)^{2}\right) / T$ using experimentally measured solubility data in the binary solvent mixture. For calculating solubility in ternary solvent mixture, eq 1 could be extended as ${ }^{7}$

$$
\begin{aligned}
\log C_{\mathrm{m}, T}^{\mathrm{Sat}}= & x_{1} \log C_{1, T}^{\mathrm{Sat}}+x_{2} \log C_{2, T}^{\mathrm{Sat}}+x_{3} \log C_{3, T}^{\mathrm{Sat}} \\
& +\frac{x_{1} x_{2}}{T} \sum_{i=0}^{2} J_{i}\left(x_{1}-x_{2}\right)^{2}+\frac{x_{1} x_{3}}{T} \sum_{i=0}^{2} J_{i}^{\prime}\left(x_{1}-x_{3}\right)^{2} \\
& +\frac{x_{2} x_{3}}{T} \sum_{i=0}^{2} J_{i}^{\prime \prime}\left(x_{2}-x_{3}\right)^{2}+\frac{x_{1} x_{2} x_{3}}{T} \sum_{i=0}^{2} J_{i}^{\prime \prime \prime}\left(x_{1}-x_{2}-x_{3}\right)^{2}
\end{aligned}
$$

where $C_{3, T}^{\text {Sat }}$ shows the molar solubility of the solute in pure solvent 3 . The constant terms of this equation can be obtained by no-intercept least-squares regression of $\log C_{\mathrm{m}, T}^{\mathrm{Sat}}-\left(x_{1} \log C_{1, T}^{\mathrm{Sat}}+\right.$ $x_{2} \log C_{2, T}^{\mathrm{at}}+x_{3} \log C_{3, T}^{\mathrm{Sat}}+\left(x_{1} x_{2} / T\right) \sum_{i=0}^{2} J_{i}\left(x_{1}-x_{2}\right)^{2}+\left(x_{1} x_{3}\right)$ T) $\left.\sum_{i=0}^{2} J^{\prime}{ }_{i}\left(x_{1}-x_{3}\right)^{2}+\left(x_{2} x_{3} / T\right) \sum_{i=0}^{2} J^{\prime \prime}{ }_{i}\left(x_{2}-x_{3}\right)^{2}\right)$ against $\left(x_{1} x_{2} x_{3} / T\right),\left(x_{1} x_{2} x_{3}\left(x_{1}-x_{2}-x_{3}\right)\right) / T$, and $\left(x_{1} x_{2} x_{3}\left(x_{1}-x_{2}-\right.\right.$ $\left.x_{3}\right)^{2}$ )/T using the experimentally measured solubility data for ternary solvent mixtures and calculated $J_{i}$ terms for the binary solvent mixtures.

For the solubility correlation of a solute in a solvent at different temperatures, the van't Hoff equation is used ${ }^{8}$

$$
\log C_{T}^{\mathrm{Sat}}=\frac{a}{T}+b
$$

where $C_{T}^{\text {Sat }}$ is the saturated molar solubility at different temperatures and $a$ and $b$ are the model constants calculated using a leastsquares method.

Comparing correlated solubilities with the corresponding experimental values, the following equation was used to calculate the mean deviation $(\mathrm{MD})$

$$
\mathrm{MD}=\frac{1}{N} \sum \frac{\left|C_{\text {cor }}-C_{\text {expt }}\right|}{C_{\text {expt }}}
$$

\section{RESULTS AND DISCUSSION}

Table 1 lists the density of the saturated solutions, experimental and correlated molar solubilities of phenothiazine along with mole fraction solubilities, and the statistical coefficients of eq 3 for water, ethanol, and propylene glycol solutions at different temperatures. Densities of the solutions gradually decrease with increased temperature which could be explained by volume expansion at higher temperatures. As expected the solubility of phenothiazine increases with increasing temperature for the three monosolvents investigated in this work. There is good agreement between the reported solubilities of phenothiazine at $298.2 \mathrm{~K}$ in water $\left(7.94 \cdot 10^{-6} \mathrm{~mol} \cdot \mathrm{L}^{-1}\right)^{1}$ and ethanol $(0.149$ $\mathrm{mol} \cdot \mathrm{L}^{-1}$ and 0.00890 mole fraction $)^{2}$ with the results of this work $\left(8.63 \cdot 10^{-6} \mathrm{~mol} \cdot \mathrm{L}^{-1}\right.$ in water; and $0.146 \mathrm{~mol} \cdot \mathrm{L}^{-1}$ and 0.00868 mole fraction in ethanol). The measured data extend the available solubility databases ${ }^{9,10}$ of drug/drug-like molecules in monosolvent systems and could be used to develop more accurate models to predict the solubility of drug candidates, which is in demand in the pharmaceutical industry. 
Table 1. Saturated Solution Densities, Experimental and Correlated Molar Solubilities, and Experimental Mole Fraction Solubility of Phenothiazine in Ethanol, Propylene Glycol, and Water at (298.2 to 338.2) $\mathrm{K}$ and Their $a$ and $b$ Constants of eq 3, Coefficient of Determination, and Mean Deviation Values

\begin{tabular}{|c|c|c|c|c|}
\hline \multirow[b]{2}{*}{$T$} & \multirow[b]{2}{*}{$\rho / \mathrm{g} \cdot \mathrm{cm}^{-3}$} & \multicolumn{2}{|c|}{$C_{\mathrm{m}, T}^{\mathrm{Sat}} / \mathrm{mol} \cdot \mathrm{L}^{-1}$} & \multirow[b]{2}{*}{ mole fraction solubility } \\
\hline & & expt. & cor. & \\
\hline \multicolumn{5}{|c|}{ Ethanol $\left(a=-661.816, b=1.377, R^{2}=0.992, \mathrm{MD}=1.2 \%\right)$} \\
\hline 298.2 & 0.797 & $1.46 \cdot 10^{-1}$ & $1.44 \cdot 10^{-1}$ & $8.76 \cdot 10^{-3}$ \\
\hline 308.2 & 0.791 & $1.65 \cdot 10^{-1}$ & $1.70 \cdot 10^{-1}$ & $1.00 \cdot 10^{-2}$ \\
\hline 318.2 & 0.787 & $1.98 \cdot 10^{-1}$ & $1.98 \cdot 10^{-1}$ & $1.22 \cdot 10^{-2}$ \\
\hline 328.2 & 0.780 & $2.31 \cdot 10^{-1}$ & $2.29 \cdot 10^{-1}$ & $1.45 \cdot 10^{-2}$ \\
\hline \multicolumn{5}{|c|}{ Propylene Glycol $\left(a=-751.620, b=1.285, R^{2}=0.984, \mathrm{MD}=3.0 \%\right)$} \\
\hline 298.2 & 1.034 & $5.59 \cdot 10^{-2}$ & $5.81 \cdot 10^{-2}$ & $4.16 \cdot 10^{-3}$ \\
\hline 308.2 & 1.030 & $7.21 \cdot 10^{-2}$ & $7.02 \cdot 10^{-2}$ & $5.40 \cdot 10^{-3}$ \\
\hline 318.2 & 1.022 & $8.66 \cdot 10^{-2}$ & $8.37 \cdot 10^{-2}$ & $6.56 \cdot 10^{-3}$ \\
\hline 328.2 & 1.017 & $1.00 \cdot 10^{-1}$ & $9.88 \cdot 10^{-2}$ & $7.63 \cdot 10^{-3}$ \\
\hline 338.2 & 1.013 & $1.11 \cdot 10^{-1}$ & $1.16 \cdot 10^{-1}$ & $8.52 \cdot 10^{-3}$ \\
\hline \multicolumn{5}{|c|}{ Water $\left(a=-1254.254, b=-0.882, R^{2}=0.985, \mathrm{MD}=4.3 \%\right)$} \\
\hline 298.2 & 0.996 & $0.86 \cdot 10^{-5}$ & $0.82 \cdot 10^{-5}$ & $1.56 \cdot 10^{-7}$ \\
\hline 308.2 & 0.994 & $1.09 \cdot 10^{-5}$ & $1.12 \cdot 10^{-5}$ & $1.98 \cdot 10^{-7}$ \\
\hline 318.2 & 0.993 & $1.39 \cdot 10^{-5}$ & $1.50 \cdot 10^{-5}$ & $2.52 \cdot 10^{-7}$ \\
\hline 328.2 & 0.992 & $1.97 \cdot 10^{-5}$ & $1.98 \cdot 10^{-5}$ & $3.58 \cdot 10^{-7}$ \\
\hline 338.2 & 0.991 & $2.70 \cdot 10^{-5}$ & $2.57 \cdot 10^{-5}$ & $4.91 \cdot 10^{-7}$ \\
\hline
\end{tabular}

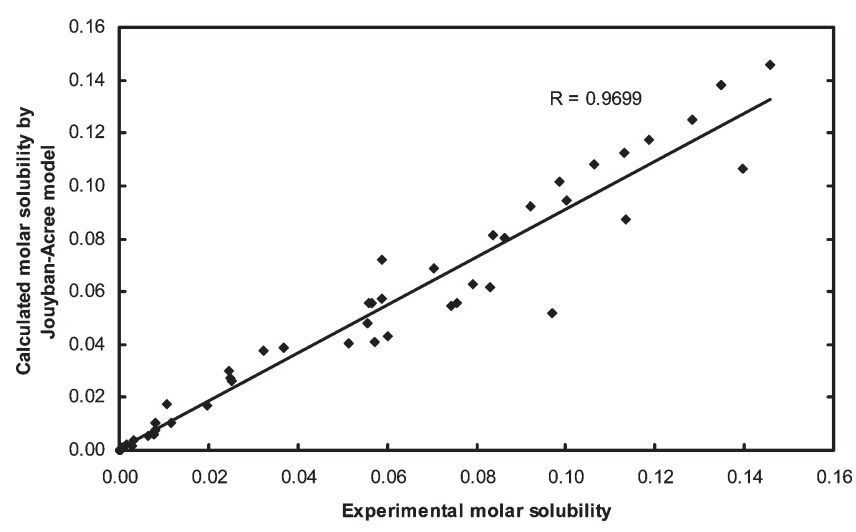

Figure 2. Calculated molar solubility of phenothiazine versus experimental values.

Table 2 gives the densities of the saturated solutions and the experimental molar and mole fraction solubilities of phenothiazine (see Figure 2) in binary and ternary solvent mixtures using the Jouyban-Acree model according to eqs 1 and 2, respectively. The generated solubility of phenothiazine in binary and ternary solvent mixtures extends the available solubility database. ${ }^{9}$ The correlated solubilities were compared with the corresponding experimental data and the computed $\mathrm{MD}$ values along with the model constants are listed in Table 3 . The overall MD value is relatively high when compared with the overall MD (i.e., $5.9 \%$ ) for the correlated solubility data using the same number of model constants. ${ }^{11}$ However, the $\mathrm{MD}$ could be considered as an acceptable error where the error of $<30 \%$ is the acceptable margin in the pharmaceutical
Table 2. Experimental Molar and Mole Fraction Solubilities of Phenothiazine in Binary and Ternary Mixture of Ethanol (1) + Propylene Glycol (2) + Water (3) and Their Densities at $298.2 \mathrm{~K}$

\begin{tabular}{|c|c|c|c|c|c|}
\hline$x_{1}$ & $x_{2}$ & $x_{3}$ & expt. (molar) & expt. (mole fraction) & $\rho / \mathrm{g} \cdot \mathrm{cm}^{-3}$ \\
\hline 1.000 & - & - & 0.145901 & $8.753 \cdot 10^{-3}$ & 0.797 \\
\hline 0.816 & 0.184 & - & 0.134649 & $8.759 \cdot 10^{-3}$ & 0.820 \\
\hline 0.663 & 0.337 & - & 0.128240 & $8.880 \cdot 10^{-3}$ & 0.837 \\
\hline 0.535 & 0.465 & - & 0.118503 & $8.526 \cdot 10^{-3}$ & 0.858 \\
\hline 0.425 & 0.575 & - & 0.113011 & $8.376 \cdot 10^{-3}$ & 0.877 \\
\hline 0.330 & 0.670 & - & 0.106290 & $7.941 \cdot 10^{-3}$ & 0.907 \\
\hline 0.247 & 0.753 & - & 0.098461 & $7.468 \cdot 10^{-3}$ & 0.925 \\
\hline 0.174 & 0.826 & - & 0.092203 & $7.044 \cdot 10^{-3}$ & 0.946 \\
\hline 0.110 & 0.890 & - & 0.083850 & $6.416 \cdot 10^{-3}$ & 0.968 \\
\hline 0.052 & 0.948 & - & 0.070415 & $5.274 \cdot 10^{-3}$ & 1.009 \\
\hline- & 1.000 & - & 0.055924 & $4.226 \cdot 10^{-3}$ & 1.018 \\
\hline 0.948 & - & 0.052 & 0.100319 & $5.559 \cdot 10^{-3}$ & 0.825 \\
\hline 0.889 & - & 0.111 & 0.083157 & $4.307 \cdot 10^{-3}$ & 0.846 \\
\hline 0.824 & - & 0.176 & 0.057088 & $2.738 \cdot 10^{-3}$ & 0.869 \\
\hline 0.751 & - & 0.249 & 0.024856 & $1.098 \cdot 10^{-3}$ & 0.890 \\
\hline 0.668 & - & 0.333 & 0.010659 & $4.322 \cdot 10^{-4}$ & 0.909 \\
\hline 0.572 & - & 0.428 & 0.008166 & $2.999 \cdot 10^{-4}$ & 0.929 \\
\hline 0.463 & - & 0.538 & 0.006371 & $2.088 \cdot 10^{-4}$ & 0.948 \\
\hline 0.334 & - & 0.666 & 0.003020 & $8.594 \cdot 10^{-5}$ & 0.963 \\
\hline 0.182 & - & 0.818 & 0.000175 & $4.129 \cdot 10^{-6}$ & 0.980 \\
\hline - & - & 1.000 & 0.000009 & $1.628 \cdot 10^{-7}$ & 0.996 \\
\hline- & 0.974 & 0.027 & 0.036979 & $2.743 \cdot 10^{-3}$ & 1.013 \\
\hline - & 0.942 & 0.058 & 0.025361 & $1.833 \cdot 10^{-3}$ & 1.011 \\
\hline - & 0.905 & 0.095 & 0.019768 & $1.389 \cdot 10^{-3}$ & 1.008 \\
\hline- & 0.859 & 0.141 & 0.011580 & $7.826 \cdot 10^{-4}$ & 1.007 \\
\hline - & 0.803 & 0.197 & 0.007907 & $5.094 \cdot 10^{-4}$ & 1.005 \\
\hline - & 0.731 & 0.269 & 0.003285 & $1.982 \cdot 10^{-4}$ & 1.003 \\
\hline - & 0.636 & 0.364 & 0.001735 & $9.518 \cdot 10^{-5}$ & 1.002 \\
\hline- & 0.505 & 0.495 & 0.000638 & $3.018 \cdot 10^{-5}$ & 1.001 \\
\hline - & 0.312 & 0.688 & 0.000389 & $1.407 \cdot 10^{-5}$ & 0.999 \\
\hline 0.186 & 0.768 & 0.046 & 0.075689 & $6.055 \cdot 10^{-3}$ & 0.863 \\
\hline 0.103 & 0.846 & 0.051 & 0.060069 & $4.623 \cdot 10^{-3}$ & 0.922 \\
\hline 0.302 & 0.623 & 0.075 & 0.096862 & $6.680 \cdot 10^{-3}$ & 0.928 \\
\hline 0.044 & 0.912 & 0.044 & 0.032218 & $2.710 \cdot 10^{-3}$ & 0.865 \\
\hline 0.494 & 0.408 & 0.098 & 0.074487 & $4.863 \cdot 10^{-3}$ & 0.866 \\
\hline 0.191 & 0.786 & 0.024 & 0.058986 & $4.728 \cdot 10^{-3}$ & 0.873 \\
\hline 0.161 & 0.829 & 0.010 & 0.086227 & $7.171 \cdot 10^{-3}$ & 0.867 \\
\hline 0.427 & 0.440 & 0.133 & 0.051492 & $3.335 \cdot 10^{-3}$ & 0.868 \\
\hline 0.053 & 0.880 & 0.066 & 0.024630 & $1.971 \cdot 10^{-3}$ & 0.887 \\
\hline 0.230 & 0.759 & 0.011 & 0.113575 & $8.793 \cdot 10^{-3}$ & 0.908 \\
\hline 0.183 & 0.756 & 0.061 & 0.055583 & $4.785 \cdot 10^{-3}$ & 0.790 \\
\hline 0.234 & 0.723 & 0.044 & 0.079084 & $5.779 \cdot 10^{-3}$ & 0.927 \\
\hline 0.186 & 0.768 & 0.046 & 0.056494 & $4.180 \cdot 10^{-3}$ & 0.928 \\
\hline 0.141 & 0.580 & 0.279 & 0.008187 & $4.487 \cdot 10^{-4}$ & 1.017 \\
\hline 0.647 & 0.333 & 0.020 & 0.139559 & $9.047 \cdot 10^{-3}$ & 0.884 \\
\hline 0.029 & 0.964 & 0.007 & 0.058752 & $5.086 \cdot 10^{-3}$ & 0.876 \\
\hline
\end{tabular}

area. ${ }^{12,13}$ It should be added that a number of data points produced relatively high deviations, including the solvent compositions of $\left(x_{1}=0.302, x_{2}=0.623, x_{3}=0.075\right),\left(x_{1}=0.334, x_{2}=0.000, x_{3}=\right.$ $0.666),\left(x_{1}=0.000, x_{2}=0.505, x_{3}=0.495\right),\left(x_{1}=0.182, x_{2}=0.000\right.$, 
Table 3. Numerical Values of the Jouyban-Acree Model Constants ( $J$ Terms) Computed Using Molar Solubilities, Number of Data Points in Each Set $(N)$, the Mean Deviation (MD) for the Correlated Solubilities of Phenothiazine in Binary and Ternary Mixture of Ethanol + Propylene Glycol + Water Using Jouyban-Acree Model, and Their Overall MD Value

\begin{tabular}{|c|c|c|c|c|c|}
\hline solvent 1 & solvent 2 & solvent 3 & $J$ terms & $N$ & $100 \cdot \mathrm{MD}$ \\
\hline \multirow[t]{4}{*}{ ethanol } & propylene & & 128.142 & 11 & 1.6 \\
\hline & glycol & & & & \\
\hline & & & -149.777 & & \\
\hline & & & 179.885 & & \\
\hline \multirow{3}{*}{$\begin{array}{c}\text { propylene } \\
\text { glycol }\end{array}$} & water & & 132.636 & 11 & 13.2 \\
\hline & & & -847.486 & & \\
\hline & & & $\mathrm{NS}^{a}$ & & \\
\hline \multirow[t]{3}{*}{ ethanol } & water & & 927.150 & 11 & 25.1 \\
\hline & & & -821.184 & & \\
\hline & & & $\mathrm{NS}^{a}$ & & \\
\hline \multirow[t]{4}{*}{ ethanol } & propylene & water & 1902.292 & 16 & 16.7 \\
\hline & & & $\mathrm{NS}^{a}$ & & \\
\hline & & & $\mathrm{NS}^{a}$ & & \\
\hline & & & & overall & 14.2 \\
\hline
\end{tabular}

$\left.x_{3}=0.818\right)$, and $\left(x_{1}=0.667, x_{2}=0.000, x_{3}=0.333\right)$ which produced the percent deviations of (34.1, 41.9, 44.4, 54.3, and 64.4)\%, respectively. By excluding these five data points the overall $\mathrm{MD}$ reduces to $10.6 \%$; however, to avoid any bias, these data points have not been excluded from the calculations. The Jouyban-Acree model could be trained at one temperature (usually $298.2 \mathrm{~K}$ ) and then used to predict the solubility of phenothiazine in the mixed solvents at other temperatures of interest employing the experimental data in monosolvents at these temperatures as shown in previous works. ${ }^{6,14}$ The generated data in monosolvents at various temperatures of Table 1 and the model constants of Table 3 could be combined to provide a predictive computational method for the solubility of phenothiazine in the ethanol + propylene glycol + water mixtures for the solubilization/desolubilization of the solute using solvent composition and/or temperature changes. This prediction method facilitates the process design and speed up the formulation and/or crystallization investigations in the pharmaceutical industry.

\section{AUTHOR INFORMATION}

\section{Corresponding Author}

*E-mail: ajouyban@hotmail.com. Fax: +98 4113363231.

\section{Funding Sources}

The authors would like to thank Drug Applied Research Center for the partial financial support under Grant No. 88-101.

\section{REFERENCES}

(1) Ohlow, M. J.; Moosmann, B. Phenothiazine: The Seven Lives of Pharmacology's First Lead Structure. Drug Discovery Today 2011, $16,119-131$.

(2) Hoover, K. R.; Acree, W. E., Jr.; Abraham, M. H. Mathematical Correlation of Phenothiazine Solubilities in Organic Solvents with the
Abraham Solvation Parameter Model. Phys. Chem. Liq. 2006, 44, 367-376.

(3) Alam, M. S.; Kabir-ud-Din; Mandal, A. B. Thermodynamics at the Cloud Point of Phenothiazine Drug Chlorpromazine Hydrochloride-Additive Systems. J. Chem. Eng. Data 2010, 55, 1693-1699.

(4) Alam, M. S.; Kabir-ud-Din; Mandal, A. B. Amphiphilic Drug Promethazine Hydrochloride-Additive System: Evaluation of Thermodynamic Parameters at Cloud Point. J. Chem. Eng. Data 2010, 55, 18931896.

(5) Alam, M. S.; Kabir-ud-Din; Mandal, A. B. Thermodynamics of Some Amphiphilic Drugs in Presence of Additives. J. Chem. Eng. Data 2010, 55, 2630-2635.

(6) Jouyban, A.; Acree, W. E., Jr. Comments on "Solubility of Ethyl Maltol in Aqueous Ethanol Mixtures”. J. Chem. Eng. Data 2009, 54, 1168-1170.

(7) Shayanfar, A.; Soltani, S.; Jabbaribar, F.; Tamizi, E.; Acree, W. E., Jr.; Jouyban, A. Anthracene Solubility in Ternary Solvent Mixtures of 2,2,4-Trimethylpentane + 2-Propanone + Alcohols at $298.15 \mathrm{~K}$. J. Chem. Eng. Data 2008, 53, 890-893.

(8) Grant, D. J. W.; Mehdizadeh, M.; Chow, A. H. L.; Fairbrother, J. E. Non-Linear van't Hoff Solubility-Temperature Plots and Their Pharmaceutical Interpretation. Int. J. Pharm. 1984, 18, 25-38.

(9) Jouyban, A. Handbook of Solubility Data for Pharmaceuticals; CRC Press: Boca Raton, FL, 2009.

(10) Yalkowsky, S. H.; He, Y.; Jain, P. Handbook of Aqueous Solubility Data, 2nd ed.; CRC Press: Boca Raton, FL, 2010.

(11) Jouyban-Gharamaleki, A.; Valaee, L.; Barzegar-Jalali, M.; Clark, B. J.; Acree, W. E., Jr. Comparison of Various Cosolvency Models for Calculating Solute Solubility in Water-Cosolvent Mixtures. Int. J. Pharm. 1999, 177, 93-101.

(12) Reillo, A.; Cordoba, M.; Escalera, B.; Selles, E.; Cordoba, M., Jr. Prediction of Sulfamethiazole Solubility in Dioxane-Water Mixtures. Pharmazie 1995, 50, 472-475.

(13) Beerbower, A.; Wu, P. L.; Martin, A. Expanded Solubility Parameter Approach 1. Naphthalene and Benzoic Acid in Individual Solvents. J. Pharm. Sci. 1984, 73, 179-188.

(14) Jouyban, A.; Shokri, J.; Barzegar-Jalali, M.; Hassanzadeh, D.; Acree, W. E., Jr.; Ghafourian, T.; Nokhodchi, A. Solubility of Chlordiazepoxide, Diazepam, and Lorazepam in Ethanol + Water Mixtures at 303.2 K. J. Chem. Eng. Data 2009, 54, 2142-2145. 